Kansas State University Libraries

New Prairie Press

\title{
USING A NONLINEAR CROSSED RANDOM EFFECTS MODEL WITH THREE-WAY TREATMENT STRUCTURE FOR DESCRIBING CIRCADIAN PATTERNS OF SERUM PROLACTIN CONCENTRATIONS IN HEAT STRESSED HOLSTEINS
}

M. Zhou
A. M. Parkhurst
B. C. Pollard
R. J. Collier

See next page for additional authors

Follow this and additional works at: https://newprairiepress.org/agstatconference

Part of the Agriculture Commons, and the Applied Statistics Commons

\section{(c) (1) $9 \odot$}

This work is licensed under a Creative Commons Attribution-Noncommercial-No Derivative Works 4.0 License.

\section{Recommended Citation}

Zhou, M.; Parkhurst, A. M.; Pollard, B. C.; and Collier, R. J. (2007). "USING A NONLINEAR CROSSED RANDOM EFFECTS MODEL WITH THREE-WAY TREATMENT STRUCTURE FOR DESCRIBING CIRCADIAN PATTERNS OF SERUM PROLACTIN CONCENTRATIONS IN HEAT STRESSED HOLSTEINS," Conference on Applied Statistics in Agriculture. https://doi.org/10.4148/2475-7772.1113

This is brought to you for free and open access by the Conferences at New Prairie Press. It has been accepted for inclusion in Conference on Applied Statistics in Agriculture by an authorized administrator of New Prairie Press. For more information, please contact cads@k-state.edu. 
Author Information

M. Zhou, A. M. Parkhurst, B. C. Pollard, and R. J. Collier

This is available at New Prairie Press: https://newprairiepress.org/agstatconference/2007/proceedings/10 


\title{
USING A NONLINEAR CROSSED RANDOM EFFECTS MODEL WITH THREE-WAY TREATMENT STRUCTURE FOR DESCRIBING CIRCADIAN PATTERNS OF SERUM PROLACTIN CONCENTRATIONS IN HEAT STRESSED HOLSTEINS
}

\author{
M. Zhou ${ }^{1}$, A.M. Parkhurst ${ }^{1}$, B.C. Pollard ${ }^{2}$, R.J. Collier ${ }^{2}$ \\ 1. Department of Statistics, University of Nebraska at Lincoln \\ 2. University of Arizona, Tucson, AZ, USA
}

\begin{abstract}
A modified Gaussian model with three-level crossed and nested random effects is used to describe circadian patterns of serum prolactin concentrations in a crossover experiment. Testing of three-way treatment effects and carryover effects are incorporated with the model building process as is the within-group correlation. We found that the interaction between environment and parity had significant effect $(\mathrm{p}<0.05)$ on both initial serum prolactin concentration and range of the prolactin concentration. There was no significant effect of recombinant bovine somatotropin (rbST) on either the initial value or concentration of serum prolactin. The inclusion of carryover effects in the model significantly improves the fit of the multilevel nonlinear mixed effects model. We present in detail a general approach to nonlinear crossed random effects model building and three-way treatment effects testing.
\end{abstract}

\section{INTRODUCTION}

Heat stress affects both the health and productivity of an animal. Acclimation to heat stress requires changes in an animal's metabolic processes which in turn change the endocrine environment. One way of evaluating changes in the endocrine environment is to assess changes in hormone concentrations such as serum prolactin, over time.

There are two objectives for this study. First, we fit a four-parameter modified Gaussian model to characterize the circadian patterns of serum prolactin of heat stressed cows. Parameters include the initial concentration of prolactin, the range of the prolactin concentration, the time to the maximum concentration, and a rate constant. Second, we compare the factor effects: environment, parity and recombinant bovine somatotropin. There are three environmental treatments (thermoneutral [TN], heat stress [HS], and heat stress plus solar radiation [HSS]) and their carryover effects, two parity levels (multiparous $[\mathrm{M}]$ and nulliparous $[\mathrm{N}]$ ), and two recombinant bovine somatotropin (rbST) treatments (with and without rbST) applied in an incomplete crossover design.

The rest of this paper is organized as follows. In Section 2, we describe the experimental design of the data and address in detail a general approach to nonlinear crossed random 
effects model building. In Section 3, we identify the significant random-effects, examine the treatment effects and test the carryover effects. In Section 4, we describe the circadian patterns of serum prolactin. Finally, in Section5, we summarize the study.

\section{MATERIALS AND METHODS}

\section{2.a Data}

Twenty-four animals were assigned to one of two studies performed in January and June, 2005 at the University of Arizona. Animals were balanced for parity and recombinant bovine somatotropin (rbST) treatment. Six of each parity (mid-lactation, multiparous (M) cows and late-gestation, nulliparous (N) cows) were assigned to each study. In each study they were randomly assigned to one of two environmental rooms and exposed to thermoneutral (TN) or one of two heat stressing environments - heat stress [HS] or heat stress plus solar [HSS], in three 14-day periods in an incomplete crossover design. Blood samples were collected on day 6 of each period at hourly intervals for 24 hours. The samples were clotted at room temperature, spun to serum, and frozen until analysis. Hormone concentrations of serum prolactin (PRL) were quantified using validated radioimmunoassay at University of Minnesota-Saint Paul, MN. An example showing serum prolactin concentration $(\log (\mathrm{ng} / \mathrm{ml}))$ for one cow is presented in Figure 1. In this example, cow \#553 (a member of the nulliparous [N] group) was observed during the third 14-day experimental period. The treatment combination was Heat Stress plus Solar [HSS] without rbST. In total, there are 36 such events in the study corresponding to the treatment structure presented in Table 1 . We limit our discussion to modeling serum prolactin changes in June but believe ideas can be extended to models for January, and leave consideration of both studies for future research efforts. 
Figure 1: Serum prolactin concentration $(\log (\mathrm{ng} / \mathrm{ml}))$ over time for cow 553 (nulliparous [N]) during third experimental period under HSS environmental treatment without rbST

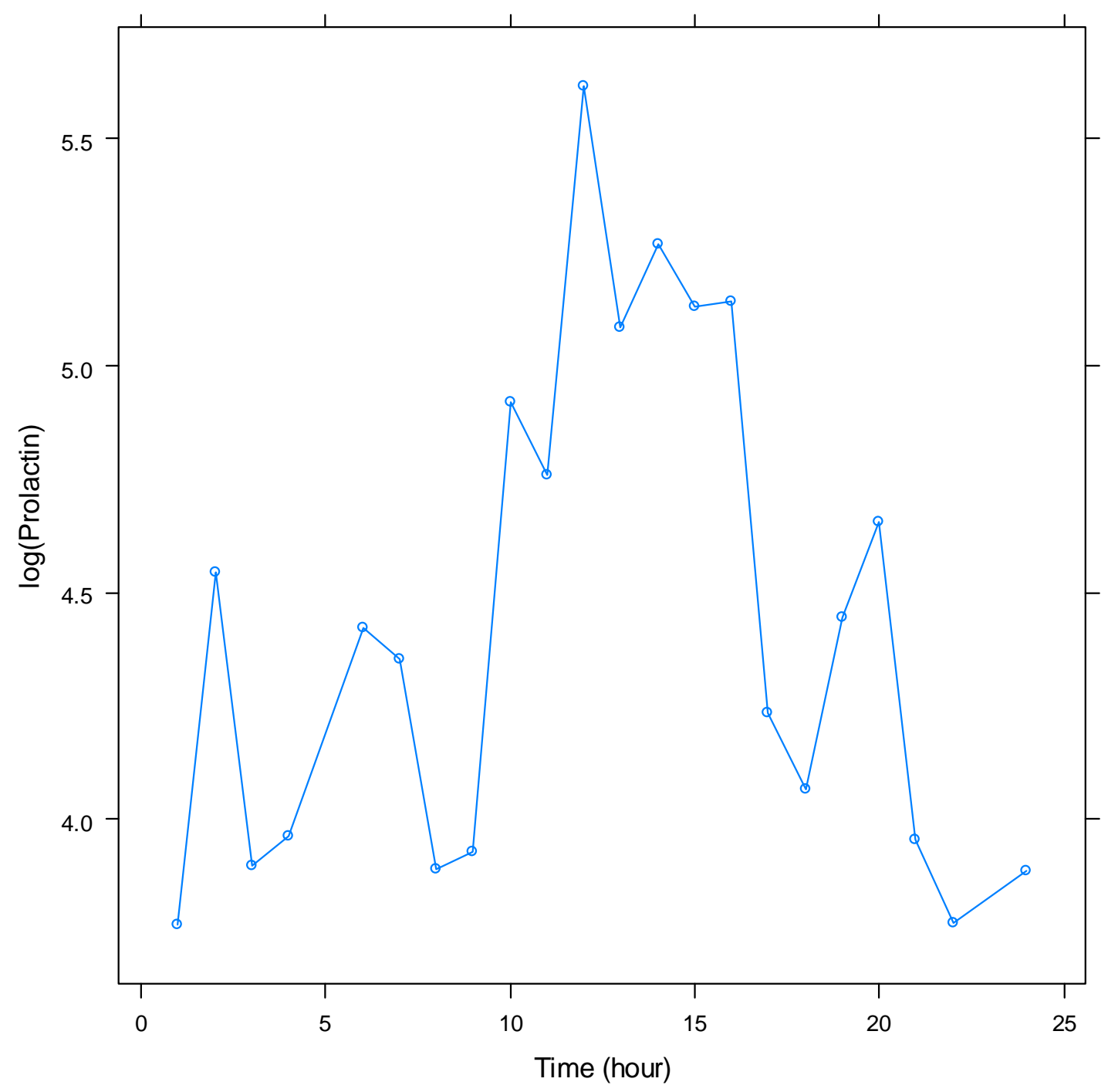

Table 1: Crossover design with three environmental treatments, twelve cows, and three periods in summer

\begin{tabular}{|c|c|c|}
\hline Environmental Room & 1 & 2 \\
\hline Cow No. & $6 \mathrm{M}$ & $6 \mathrm{~N}$ \\
\hline Period 1 & HS & TN \\
\hline Period 2 & TN & HSS \\
\hline Period 3 & HSS & HS \\
\hline
\end{tabular}




\section{2.b Statistical Model}

We use a four-parameter modified Gaussian model to model the patterns of serum prolactin concentrations of cows over time. The model is given by

$$
\mathrm{Y}=\mathrm{Y} 0+\Delta \cdot \exp \left(-(\mathrm{X}-\tau)^{2} / \varsigma\right)+\varepsilon, \quad \varepsilon \sim \operatorname{iidN}\left(0, \sigma^{2} \Psi\right)
$$

where the response variable, $\mathrm{Y}$, is the logarithm of the serum prolactin concentration $(\log (\mathrm{ng} / \mathrm{ml}))$ and the independent variable, $\mathrm{X}$, is the time (hour) at which blood samples were taken. There are four parameters in the model: Y0 is the logarithm of the baseline (initial) serum prolactin concentration $(\log (\mathrm{ng} / \mathrm{ml})), \Delta$ is the range (the difference between the maximum and baseline concentrations), $\tau$ is the time to the maximum concentration (hours), and $\zeta$ is a rate constant (hour ${ }^{-1}$ ). The physical meaning of the rate constant $\zeta$ merits an illustration. Figure 2 shows patterns of prolactin concentration governed by different rate constants, $\zeta$. The larger $\zeta$ is the longer it takes the prolactin concentration to return to its initial value. The rate constant $\zeta$ can also be considered as a measure of the spread of the change of prolactin concentration.

Figure 2: Examples of the logarithm of the serum prolactin concentration, $Y$, vs the time, $X$, for three values of the rate constant, $\zeta$.

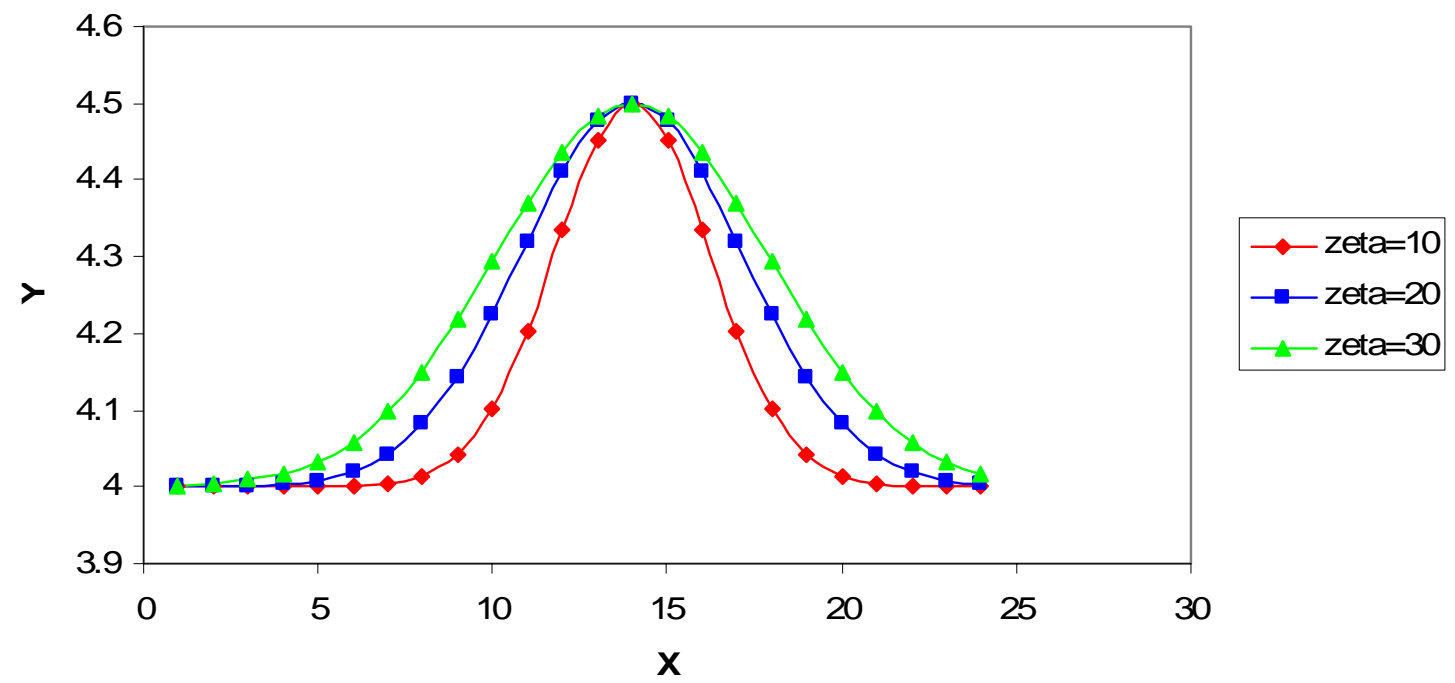

The thermal environmental treatment, parity, rbST treatment, and cross-over effects and crossed random effects are incorporated in the modified Gaussian model through the four population parameters (Eq. 1). There are different choices available for choosing contrasts for fixed-effects terms. In our study, the thermal environmental treatment contains three levels. Therefore, we use the Helmert contrasts to construct orthogonal contrasts. A detailed model specification is given in Eq. 2.

$$
\mathrm{Y}=\mathrm{Y} 0+\Delta \cdot \exp \left(-(\mathrm{X}-\tau)^{2} / \varsigma\right)+\varepsilon, \quad \varepsilon \sim \operatorname{iidN}\left(0, \sigma^{2} \Psi\right) \text { and }
$$




$$
\begin{aligned}
& \mathrm{Y} 0=\mathrm{C} \beta_{1}+\mathrm{Zb}_{1} \text {, } \\
& \Delta=\mathrm{C} \beta_{2}+\mathrm{Zb}_{2} \text {, } \\
& \tau=\mathrm{C} \beta_{3}+\mathrm{Zb}_{3} \text {, } \\
& \varsigma=\mathrm{C} \beta_{4}+\mathrm{Zb}_{4} \text {, } \\
& \mathrm{C}=\left[\underline{1}\left|\mathrm{C}_{1}\right| \mathrm{C}_{2}\left|\mathrm{C}_{3}\right| \mathrm{C}_{4}\left|\mathrm{C}_{1} \mathrm{C}_{2}\right| \mathrm{C}_{1} \mathrm{C}_{3}\left|\mathrm{C}_{1} \mathrm{C}_{4}\right| \mathrm{C}_{2} \mathrm{C}_{3}\left|\mathrm{C}_{2} \mathrm{C}_{4}\right| \mathrm{C}_{1} \mathrm{C}_{2} \mathrm{C}_{3}\left|\mathrm{C}_{1} \mathrm{C}_{2} \mathrm{C}_{4}\right| \mathrm{C}_{5} \mid \mathrm{C}_{6}\right] \text {, } \\
& \beta_{\ell}=\left[\begin{array}{c}
\beta_{\ell 1} \\
\beta_{\ell 2} \\
\vdots \\
\beta_{\ell 14}
\end{array}\right] \text {, }
\end{aligned}
$$

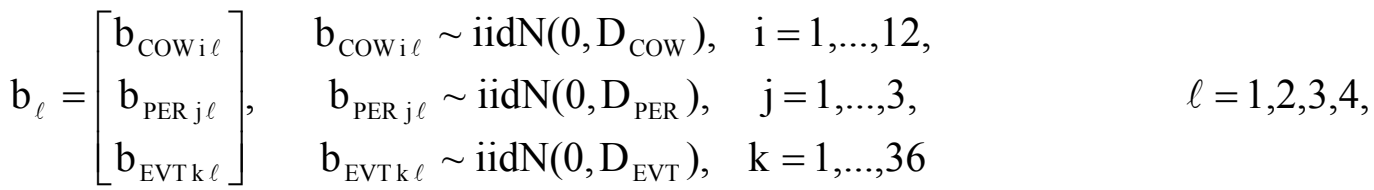

$$
\begin{aligned}
& \mathrm{C}_{1}=\left\{\begin{array}{c}
-1, \text { Parity }=\text { Nulliparous, } \\
1, \text { Parity }=\text { Mulliparous, }
\end{array} \quad \mathrm{C}_{2}=\left\{\begin{array}{c}
-1, \text { without } \mathrm{rbST}, \\
1, \text { with rbST, }
\end{array}\right.\right. \\
& \mathrm{C}_{3}=\left\{\begin{array}{rl}
-1, \text { Environment } & =\mathrm{HS}, \\
1, \text { Environment } & =\mathrm{HSS}, \\
0, \text { Environment } & =\mathrm{TN},
\end{array} \quad \mathrm{C}_{4}=\left\{\begin{array}{c}
-1, \text { Environment }=\mathrm{HS}, \\
-1, \text { Environment }=\mathrm{HSS}, \\
2, \text { Environment }=\mathrm{TN},
\end{array}\right.\right. \\
& \mathrm{C}_{5}=\left\{\begin{array}{l}
1, \text { Environmental treatment } \\
\text { in previous period is HS, } \\
0, \text { else, }
\end{array}\right. \\
& \mathrm{Z}=\text { matrix of } 1 \text { 's, }
\end{aligned}
$$

where the $\beta_{\ell 1}$ 's represent the overall means of Y0, $\Delta, \tau$, and $\zeta$ corresponding to $\ell=1,2,3,4$ respectively; the $\beta_{\ell 2}$ 's represent the parity main effects; the $\beta_{\ell 3}$ 's represent the rbST main effects; $\beta_{\ell 4}$ 's and $\beta_{\ell 5}$ 's represent the environment main effects; the $\beta_{\ell 6}$ 's represent the parity-rbST interactions; $\beta_{\ell 7}$ 's and $\beta_{\ell 8}$ 's represent the parity-environment interactions; $\beta_{\ell 9}$ 's and $\beta_{\ell 10}$ 's represent the rbST-environment interactions; $\beta_{\ell 11}$ 's and $\beta_{\ell 12}$ 's represent the parity-rbST-environment interactions; the $\beta_{\ell 13}$ 's represent the firstorder carryover effects of environmental treatment HS; the $\beta_{\ell 14}$ 's represent the first-order carryover effects of the third environmental treatment HSS. The random effects $\mathrm{b}_{\text {Cow } i \ell}$ represent the deviation from the population mean associated with the $i^{\text {th }}$ cow, similarly,

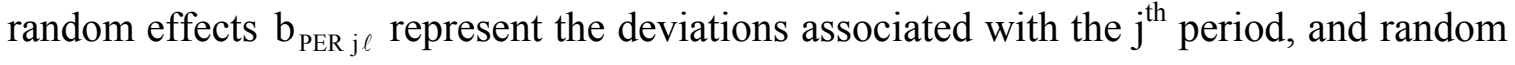
effects $\mathrm{b}_{\mathrm{EVT} \ell}$ represent the deviations associated with the $\mathrm{k}^{\text {th }}$ event for $\ell=1,2,3,4$. We further assume that $b_{\mathrm{COW}}, \mathrm{b}_{\mathrm{PERj}}, \mathrm{b}_{\mathrm{EVTk}}$, and $\varepsilon$ are independent. 


\section{2.c Crossed Random Effects}

In our study, cow and period are crossed with each other and event is nested within the combination of cow and period. The random-effects associated with cow and period are called crossed random effects.

\section{2.d Model Building}

\section{2.d.i Random Effects Specification}

We start with the multilevel nonlinear mixed effects model with no treatments or covariates to explain random-effects variation. In Eq. 1 the within-event errors, $\varepsilon$, are initially assumed to be independent $\mathrm{N}\left(0, \sigma^{2} \Psi\right)$, where $\Psi=\mathrm{I}$ represents the identity matrix. In Eq. 2 all four parameters are initially considered to be mixed, including a fixed population mean and random effects for cow-, period-, and event-levels. To avoid convergence problems with the optimization algorithm used in NLME (Pinheiro and Bates, 2000), a diagonal structure is assumed for the variance-covariance matrices $\mathrm{D}_{\mathrm{COW}}$, $\mathrm{D}_{\mathrm{PER}}$, and $\mathrm{D}_{\mathrm{EVT}}$. Under these assumptions, Eq. 1 and Eq. 2 are fit and the random-effect terms with near-zero or extremely small standard deviations are removed if the likelihood ratio test (LRT) is non-significant. In this way, a model is obtained including all significant random-effect terms under the assumptions of diagonal variance-covariance matrices of random effects and independence of within-event error with no treatments or covariates. Next the variance-covariance matrices of random effects are changed from diagonal to unconstrained structure, and the model is fit again using the LRT to determine if the unconstrained structure significantly improves the fit of the multilevel nonlinear mixed effects model as before.

\section{2.d.ii Incorporation of Treatment Factors and Covariates}

After identifying the significant random-effects, we include the three-way treatment design (three-environment $\times$ two-parity $\times$ two-rbST) and the first-order carryover effects of the environmental treatments in a multilevel nonlinear mixed effects model to determine useful (significant) covariates. The fixed-effect terms with large p-values are removed if the LRT is non-significant. In this way, a model is obtained including all significant fixed-effect terms.

\section{2.d.iii Model Diagnostics}

After the random- and fixed-effect specification, a plot of standardized residuals versus fitted values is used to investigate departure from model assumptions. The normality assumption for the within-event errors is investigated by the normal quantile plot of the standardized residuals. We also investigate the need for within-event heterogeneity and correlation structures in the nonlinear mixed effects model by looking at plots of the normalized residuals and the empirical autocorrelation function (ACF) respectively; we assess the adequacy of the variance and correlation structures for within-event errors by re-examining diagnostic plots. A final assessment of the adequacy of the nonlinear mixed-effects model is taken by a plot of the augmented predictions. If diagnostics show that all the assumptions are satisfied, we then use the model to compare treatment effects over time. 


\section{2.e Fitting Multilevel Nonlinear Mixed Models with both Crossed and Nested Random Effects in R: NLME}

Fitting nonlinear mixed models with both crossed and nested random effects is still a new and challenging topic in statistics. Zhou, Parkhurst, et al (2006) evaluate three procedures (NLME function in R [Pinheiro and Bates, 2000], \%NLINMIX macro in SAS [Wolfinger, 1993], and random effects modeling in AD Model Builder [Skaug and Fournier, 2006]) to fit a multilevel nonlinear mixed effects model with both crossed and nested random effects applied in a Latin Square design. They recommend using the readily assessable NLME function in $\mathrm{R}$ to get computational efficiency and achieve accurate estimates. In this study, we fit the multilevel nonlinear mixed effects model with the NLME function.

The NLME package in R is very powerful for fitting multilevel nonlinear mixed-effects models with nested random effects, but it does not fit nonlinear mixed-effects models with crossed random effects (Pinheiro and Bates, 2000). Rasbash and Goldstein (1994) show how to fit a linear mixed model with crossed random effects as a purely hierarchical formulation of nested random effects. Zhou, Parkhurst, et al (2006) developed a method to enable NLME in R to fit a nonlinear mixed-effects model with crossed random effects based on Rasbash and Goldstein's idea for linear mixed-effects model. This method can be used to fit a nonlinear mixed effects model with arbitrary levels of crossed and nested random effects. However, only one correlation for the crossed random effects can be estimated. The NLME code for fitting the nonlinear mixed-effects model formulated by Eq. 1 and Eq. 2 without treatments and covariates and further assuming diagonal $\mathrm{D}_{\mathrm{COW}}, \mathrm{D}_{\mathrm{PER}}$, and $\mathrm{D}_{\mathrm{EVT}}$, and independent errors $(\mathrm{e} . \mathrm{g} . \mathrm{\Psi}=\mathrm{I})$ is documented in the Appendix.

\section{RESULTS AND DISCUSSION}

\section{3.a Specification of Random Effects}

We started with the multilevel nonlinear mixed effects model without treatments and covariates to explain random-effects variation. Diagonal structures of the variancecovariance matrices were initially assumed for $\mathrm{D}_{\mathrm{COW}}, \mathrm{D}_{\mathrm{PER}}$, and $\mathrm{D}_{\mathrm{EVT}}$ and we also assumed the within-event errors, $\varepsilon$, to be independent. We removed one random effect term from the parameters at a time. This resulted in several models with different random-effects components (Table 2). Since the reduced models are nested within the full model and the same fixed-effects structures are used, LRTs can be used to check if the reduction in random effects caused any significant changes in model performance. Comparisons of the eight models are shown in Table 3. The nearly identical LogLikelihoods, the big p-value, and the smallest AIC and BIC all suggest that Model 8 has the best parsimonious performance. That is to say, the cow-level random effect associated with $\Delta$, and the period-, cow-, and event-level random effects associated with $\tau$ and $\zeta$ can be safely dropped from the full model. Starting with Model 8, we assume that all period-, cow-, and event-level random effects are correlated, which results in Model 9. 
The fitting comparison of Model 8 with Model 9 indicates that the LRT is not significant at 5\% level ( $p$-value=.6459). Therefore, Model 8 with diagonal variance-covariance matrices of period- and event-level random-effects is preferable over Model 9 with an unconstrained variance-covariance structure of random-effects.

Table 2: Nonlinear Mixed Model with Different Random-Effects Components

\begin{tabular}{|c|c|c|c|c|c|c|c|c|c|c|c|c|}
\hline \multirow{2}{*}{ Model } & \multicolumn{4}{|c|}{ Period } & \multicolumn{4}{c|}{ Cow } & \multicolumn{5}{c|}{ Event } \\
\cline { 2 - 13 } & $\mathrm{Y} 0$ & $\Delta$ & $\mathrm{T}$ & $\Gamma$ & $\mathrm{Y} 0$ & $\Delta$ & $\mathrm{T}$ & $\Gamma$ & $\mathrm{Y} 0$ & $\Delta$ & $\mathrm{T}$ & $\Gamma$ \\
\hline 1 & .180 & .158 & $1 \mathrm{e}-4$ & .017 & .143 & $2 \mathrm{e}-6$ & $2 \mathrm{e}-4$ & .004 & .403 & .434 & $2 \mathrm{e}-4$ & $5 \mathrm{e}-15$ \\
\hline 2 & .171 & .158 & $3 \mathrm{e}-4$ & .140 & $8 \mathrm{e}-4$ & $4 \mathrm{e}-6$ & $3 \mathrm{e}-4$ & .150 & .430 & .432 & $9 \mathrm{e}-4$ & \\
\hline 3 & .171 & .158 & $5 \mathrm{e}-4$ & .137 & .001 & & $6 \mathrm{e}-4$ & .147 & .430 & .432 & $7 \mathrm{e}-4$ & \\
\hline 4 & .171 & .158 & & .139 & .002 & & .001 & .149 & .430 & .432 & .001 & \\
\hline 5 & .180 & .158 & & .092 & .143 & & & .092 & .403 & .434 & .003 & \\
\hline 6 & .180 & .158 & & .012 & .143 & & & $2 \mathrm{e}-4$ & .403 & .434 & & \\
\hline 7 & .180 & .158 & & .122 & .143 & & & & .403 & .434 & & \\
\hline 8 & .180 & .158 & & & .143 & & & & .403 & .434 & & \\
\hline
\end{tabular}

Table 3: Comparisons of Model Fit with Different Random-Effects Components

\begin{tabular}{|c|c|c|c|c|c|}
\hline Model $^{*}$ & AIC & BIC & Log-Likelihood & LRT $^{\dagger}$ & p-value \\
\hline 1 & 1486.057 & 1566.666 & -726.0283 & & \\
\hline 2 & 1484.354 & 1560.222 & -726.1772 & .298 & .585 \\
\hline 3 & 1482.354 & 1553.480 & -726.1772 & .298 & .862 \\
\hline 4 & 1480.354 & 1546.738 & -726.1772 & .298 & .961 \\
\hline 5 & 1478.065 & 1539.708 & -726.0327 & .009 & $>.999$ \\
\hline 6 & 1476.066 & 1532.967 & -726.0332 & .010 & $>.999$ \\
\hline 7 & 1474.066 & 1526.225 & -726.0333 & .010 & $>.999$ \\
\hline 8 & 1472.073 & 1519.490 & -726.0365 & .016 & $>.999$ \\
\hline
\end{tabular}

${ }^{*}$ Model as described in Table 2.

${ }^{\dagger}$ Log-Likelihood Ratio Test is calculated with respect to model [1].

\section{3.b Inclusion of Treatments and Carryover Effects}

After the specifications of random-effects, Model 10 was obtained with the inclusion of the three-way treatment effects and the first-order carryover effects to those parameters in Model 8 associated with random effects. We then removed one fixed effect term from the parameters at a time if the model converged, which also resulted in several models with different fixed-effect structures (Table 4). Again, LRTs were used to check if the reduction in fixed effects caused any significant changes in model performance. Comparisons of the ten models are showed in Table 5. The similar Log-Likelihoods, the big p-value, and the smallest AIC and BIC all suggest that Model 20 has the best performance. The normal plot of the standardized residuals, shown in Figure 3, does not show any violations of the normality assumption for the within-event errors, except for a few possible outlying observations which are located out \pm 2 standard deviation. The assessment of the adequacy of the nonlinear mixed-effects model is given by the plot of the augmented predictions in Figure 4. From the plot, we can see that the predicted serum prolactin concentrations are close to the observed values. The plot of the augmented predictions and other diagnostic plots show that the nonlinear mixed-effects 
model (Model 20) provides a reasonable representation of the serum prolactin concentrations of heat stressed cows. We therefore use Model 20 to determine the useful covariates and to compare treatment effects over time.

Table 4: Nonlinear Mixed Model with Different Fixed-Effects Structures

\begin{tabular}{|c|c|c|c|c|c|c|c|c|c|c|c|c|}
\hline \multirow{2}{*}{\multicolumn{2}{|c|}{ Fixed Effects }} & \multicolumn{11}{|c|}{ Model } \\
\hline & & 10 & 11 & 12 & 13 & 14 & 15 & 16 & 17 & 18 & 19 & 20 \\
\hline \multirow{2}{*}{ Carryover: HS } & Y0 & + & & & & & & & & & & \\
\hline & $\Delta$ & + & + & + & & & & & & & & \\
\hline \multirow{2}{*}{ Carryover: HSS } & $\mathrm{Y0}$ & + & + & + & + & + & + & + & + & + & + & + \\
\hline & $\Delta$ & + & + & + & + & + & + & + & + & + & & \\
\hline \multirow{2}{*}{ Parity } & Y0 & + & + & + & + & + & + & + & + & + & + & + \\
\hline & $\Delta$ & + & + & + & + & + & + & + & + & + & + & + \\
\hline \multirow{2}{*}{$\mathrm{rbST}$} & $\mathrm{Y0}$ & + & + & + & + & + & + & + & + & & & \\
\hline & $\Delta$ & + & + & + & + & + & + & + & + & + & + & \\
\hline \multirow{2}{*}{ Environment } & Y0 & + & + & + & + & + & + & + & + & + & + & + \\
\hline & $\Delta$ & + & + & + & + & + & + & + & + & + & + & + \\
\hline \multirow{2}{*}{ Parity $\times$ rbST } & Y0 & + & + & + & + & + & + & & & & & \\
\hline & $\Delta$ & + & + & + & + & & & & & & & \\
\hline \multirow{2}{*}{ Environment $\times$ Parity } & Y0 & + & + & + & + & + & + & + & + & + & + & + \\
\hline & $\Delta$ & + & + & + & + & + & + & + & + & + & + & + \\
\hline \multirow{2}{*}{ Environment $\times$ rbST } & Y0 & + & + & + & + & + & + & + & & & & \\
\hline & $\Delta$ & + & + & + & + & + & + & + & + & + & + & \\
\hline \multirow{2}{*}{ 3-way Interaction } & Y0 & + & + & + & + & + & & & & & & \\
\hline & $\Delta$ & + & + & & & & & & & & & \\
\hline
\end{tabular}

Table 5: Comparisons of Model Fit with Different Fixed-Effects Structures

\begin{tabular}{|c|c|c|c|c|c|}
\hline Model $^{*}$ & AIC & BIC & Log-Likelihood & LRT $^{\dagger}$ & p-value \\
\hline 10 & 1456.651 & 1627.352 & -692.3253 & & \\
\hline 11 & 1454.656 & 1620.616 & -692.3281 & .006 & .941 \\
\hline 12 & 1450.754 & 1607.230 & -692.3772 & .104 & .991 \\
\hline 13 & 1448.801 & 1600.535 & -692.4005 & .150 & .997 \\
\hline 14 & 1447.216 & 1594.209 & -692.6082 & .566 & .990 \\
\hline 15 & 1445.779 & 1583.288 & -693.8895 & 3.128 & .873 \\
\hline 16 & 1444.144 & 1576.912 & -694.0720 & 3.493 & .900 \\
\hline 17 & 1440.367 & 1563.651 & -694.1832 & 3.716 & .959 \\
\hline 18 & 1439.254 & 1557.797 & -694.6271 & 4.604 & .949 \\
\hline 19 & 1438.153 & 1551.954 & -695.0766 & 5.503 & .939 \\
\hline 20 & 1436.973 & 1536.549 & -697.4866 & 10.32265 & .799 \\
\hline
\end{tabular}

Model as described in Table 4.

${ }^{\dagger}$ Log-Likelihood Ratio Test is calculated with respect to model [10]. 
Figure 3: Normal plot of standardized residuals for Model 20

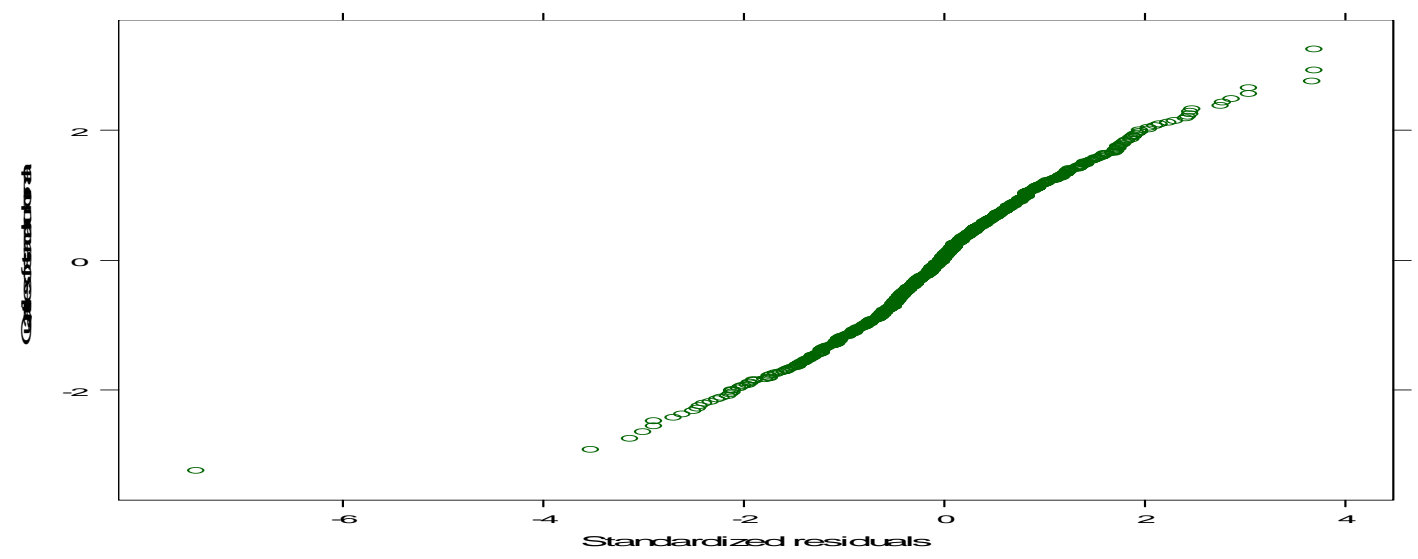

Figure 4: Observed (0) and predicted (--) serum prolactin concentrations $(\log (\mathrm{ng} / \mathrm{ml})$ ) over time (hour) for thirty-six cow-by-period events

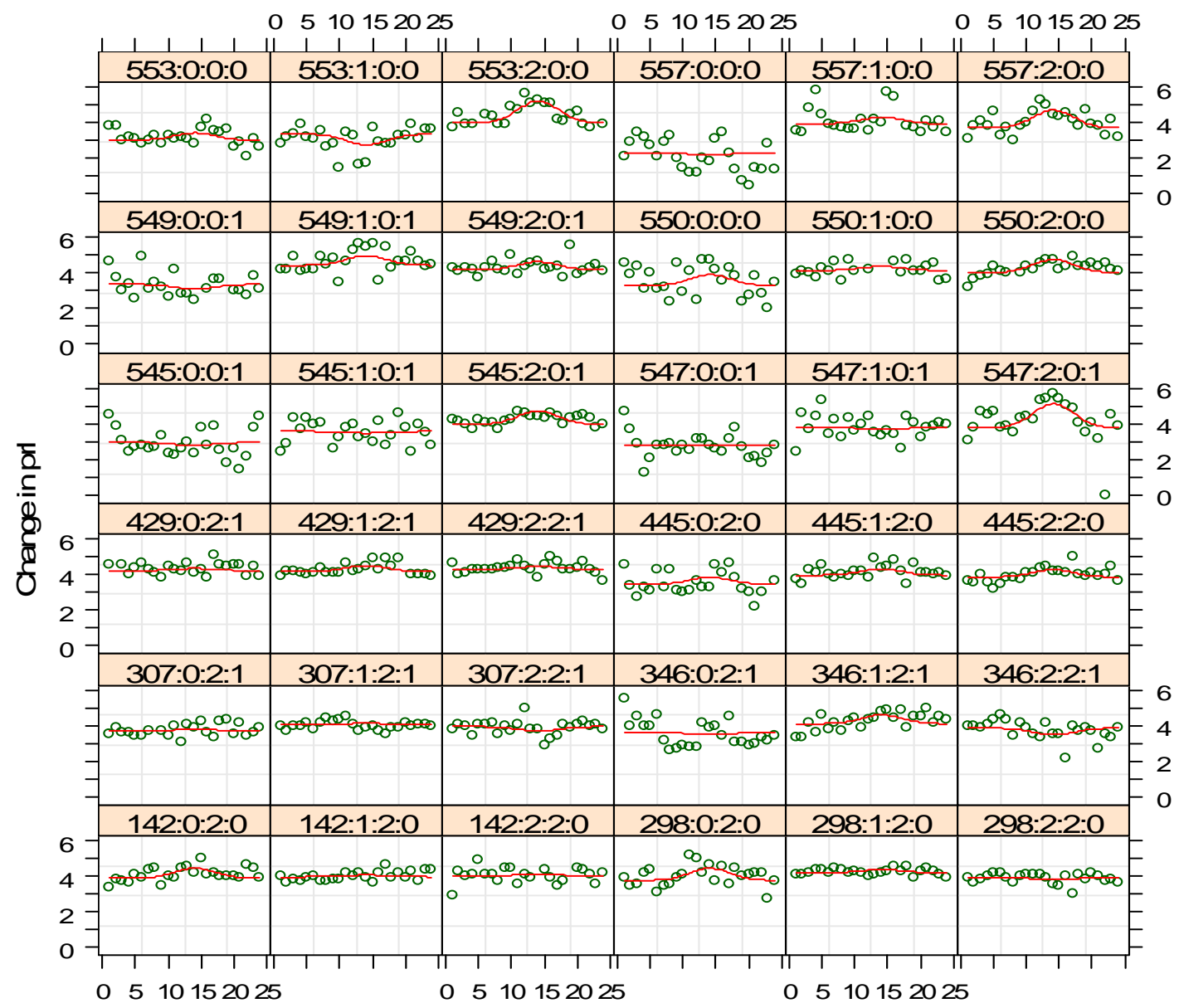

hour 


\section{3.c Comparison of the Three-Way Treatment Effects and Test of the First-order Carryover Effects}

We compare the three-way treatment effects and test the first-order carryover effects based on the results from Model 20 (Table 6). We found that the interaction between environment and parity had significant effect on both Y0 and $\Delta$ since, for $\beta_{18}$ and $\beta_{27}, \mathrm{p}<$ 0.05 . There was no significant effect of rbST on either Y0 or $\Delta$ ( $\mathrm{rbST}$ is not in Model $20)$. The first-order carryover effect of HSS had a significant effect on Y0 $\left(\beta_{114}, \mathrm{p}=\right.$ $0.014)$. In fact, it increased Y0 by $0.367 \log (\mathrm{ng} / \mathrm{ml})$. The cell mean for each combination of environment and parity is shown in Table 7. The interaction plots for Y0 and $\Delta$ shown in Figure 5 are constructed using the cell means in Table 7. Table 8 and Figure 6 show the $95 \%$ confidence intervals for each combination of environment and parity for $\mathrm{Y} 0$ and $\Delta$.

From Figures 5 and 6, we found that Y0 was significantly lower for TN-N than for other combinations of environment and parity. The initial estimate, $\mathrm{Y} 0$ for $\mathrm{TN}$ and $\mathrm{N}$ is the lowest (2.963) and its 95\% CI does not overlap with other 95\% CI's. There is considerable overlap in the remaining set of Environment and Parity 95\% CI's. Therefore, for nulliparous cows, Y0 increased under heat stress (HS and HSS) compared to the thermoneutral environment $\mathrm{TN}$; however, for $\mathrm{TN}$-multiparous cows, $\mathrm{Y} 0$ was already high and neither HS nor HSS showed a significant increase in Y0.

Examination of the range in Table 7 showed the only $\Delta$ significantly greater than zero was for nulliparous cows under solar heat stress (HSS-N, $\mathrm{p}<0.001)$. Therefore, for nulliparous cows, $\Delta$ increased significantly when exposed to HSS compared to those nulliparous cows in TN or HS environment. For multiparous cows, environment had no significant effect on $\Delta$.

Table 6: Estimates of Fixed Effects Coefficients for Model 20

\begin{tabular}{|c|c|c|c|c|}
\hline \multicolumn{1}{|c|}{ Fixed Effects } & Estimate & Std. Err. & P-value \\
\hline \multirow{4}{*}{ Y0 } & Overall mean: $\beta_{11}$ & 3.708 & .071 & $<.001$ \\
\cline { 2 - 5 } & Parity: N vs. M: $\beta_{12}$ & .084 & .061 & .167 \\
\cline { 2 - 5 } & HS vs. HSS: $\beta_{14}$ & -.172 & .030 & $<.001$ \\
\cline { 2 - 5 } & TN vs. HS \& HSS: $\beta_{15}$ & -.174 & .067 & .009 \\
\cline { 2 - 5 } & $\left(\mathrm{N}\right.$ vs. M)*(HS vs. HSS): $\beta_{17}$ & .037 & .049 & .447 \\
\cline { 2 - 5 } & $\left(\mathrm{N}\right.$ vs. M)*(TN vs. HS \& HSS): $\beta_{18}$ & -.116 & .028 & $<.001$ \\
\cline { 2 - 5 } & Carryover Effect of HSS: $\beta_{114}$ & .367 & .149 & .014 \\
\hline \multirow{4}{*}{$\Delta$} & Overall mean: $\beta_{21}$ & .266 & .118 & .024 \\
\cline { 2 - 5 } & Parity: N vs. M: $\beta_{22}$ & .151 & .095 & .112 \\
\cline { 2 - 5 } & HS vs. HSS: $\beta_{24}$ & .007 & .054 & .900 \\
\cline { 2 - 5 } & TN vs. HS \& HSS: $\beta_{25}$ & .085 & .071 & .230 \\
\cline { 2 - 5 } & $\left(\mathrm{N}\right.$ vs. M)*(HS vs. HSS): $\beta_{27}$ & .287 & .087 & .001 \\
\hline & $\left(\mathrm{N}\right.$ vs. M)*(TN vs. HS \& HSS): $\beta_{28}$ & -.098 & .050 & .051 \\
\hline \multirow{3}{*}{$\tau$} & 14.076 & .327 & $<.001$ \\
\hline
\end{tabular}


Table 7: Cell means for each combination of environment and parity

\begin{tabular}{|c|c|c|c|c|c|}
\hline Parameter & Environment & Parity & Estimate & Std.Error & p-value \\
\hline Y0 & TN & $\mathrm{N}$ & 2.963 & .118 & $<.001$ \\
\hline Y0 & TN & $\mathrm{M}$ & 3.769 & .119 & $<.001$ \\
\hline Y0 & $\mathrm{HS}$ & $\mathrm{N}$ & 3.701 & .139 & $<.001$ \\
\hline $\mathrm{Y} 0$ & $\mathrm{HS}$ & $\mathrm{M}$ & 3.888 & .138 & $<.001$ \\
\hline $\mathrm{Y} 0$ & $\mathrm{HSS}$ & $\mathrm{N}$ & 3.935 & .125 & $<.001$ \\
\hline $\mathrm{Y} 0$ & $\mathrm{HSS}$ & $\mathrm{M}$ & 3.985 & .118 & $<.001$ \\
\hline$\Delta$ & $\mathrm{TN}$ & $\mathrm{N}$ & .145 & .208 & .487 \\
\hline$\Delta$ & $\mathrm{TN}$ & $\mathrm{M}$ & .370 & .208 & .075 \\
\hline$\Delta$ & $\mathrm{HS}$ & $\mathrm{N}$ & .013 & .212 & .953 \\
\hline$\Delta$ & $\mathrm{HS}$ & $\mathrm{M}$ & .222 & .207 & .284 \\
\hline$\Delta$ & $\mathrm{HSS}$ & $\mathrm{N}$ & .883 & .208 & $<.001$ \\
\hline$\Delta$ & $\mathrm{HSS}$ & $\mathrm{M}$ & -.053 & .208 & .799 \\
\hline
\end{tabular}

Table 8: $95 \%$ Confidence Intervals for Initial value, Y0 and Range, $\Delta$

\begin{tabular}{|c|c|c|c|c|c|}
\hline Parameter & Environment & Parity & Lower & Estimate & Upper \\
\hline Y0 & TN & N & 2.731 & 2.963 & 3.195 \\
\hline Y0 & TN & M & 3.535 & 3.769 & 4.003 \\
\hline Y0 & HS & N & 3.429 & 3.701 & 3.973 \\
\hline Y0 & HS & M & 3.617 & 3.888 & 4.159 \\
\hline Y0 & HSS & N & 3.690 & 3.935 & 4.180 \\
\hline Y0 & HSS & M & 3.753 & 3.985 & 4.217 \\
\hline$\Delta$ & TN & N & -.263 & .145 & .553 \\
\hline$\Delta$ & TN & M & -.037 & .370 & .778 \\
\hline$\Delta$ & HS & N & -.403 & .0126 & .428 \\
\hline$\Delta$ & HS & $\mathrm{M}$ & -.184 & .222 & .628 \\
\hline$\Delta$ & HSS & N & .476 & .883 & 1.291 \\
\hline$\Delta$ & HSS & M & -.462 & -.053 & .355 \\
\hline
\end{tabular}


Figure 5: Interaction Plots for Initial Value Y0 and Range, $\Delta$.

\section{Interaction Plot: Y0}

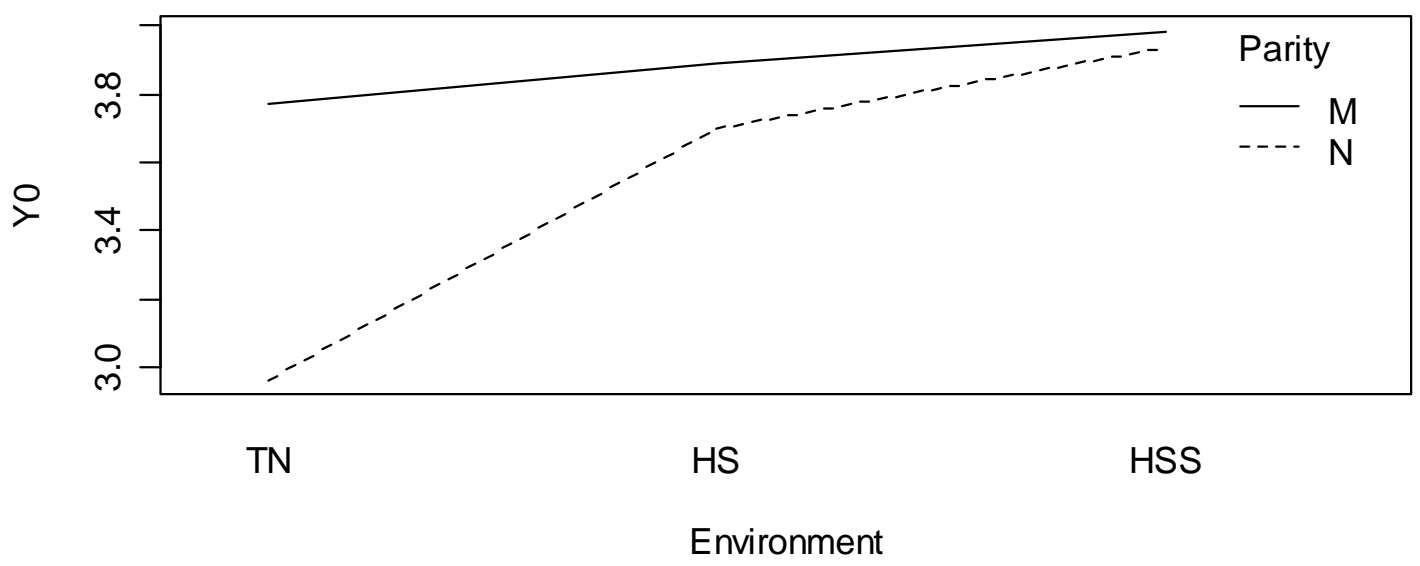

Interaction Plot: DELTA

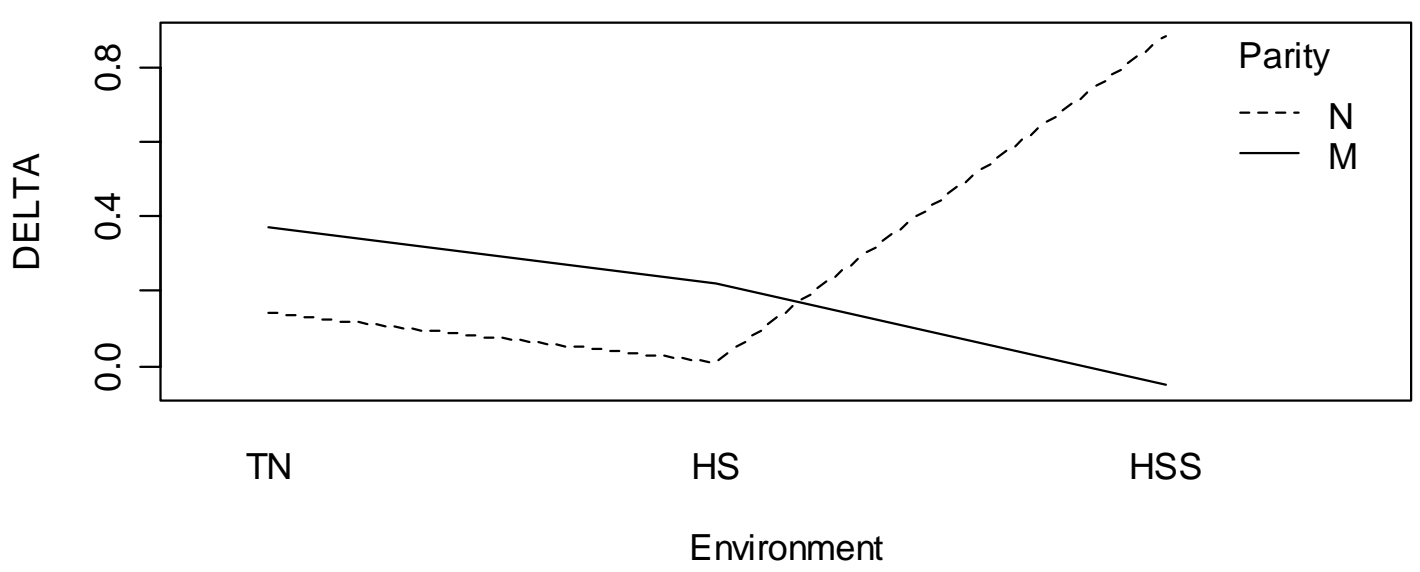


Figure 6: $95 \%$ Confidence Intervals for Initial Value, Y0 and Range, $\Delta$.
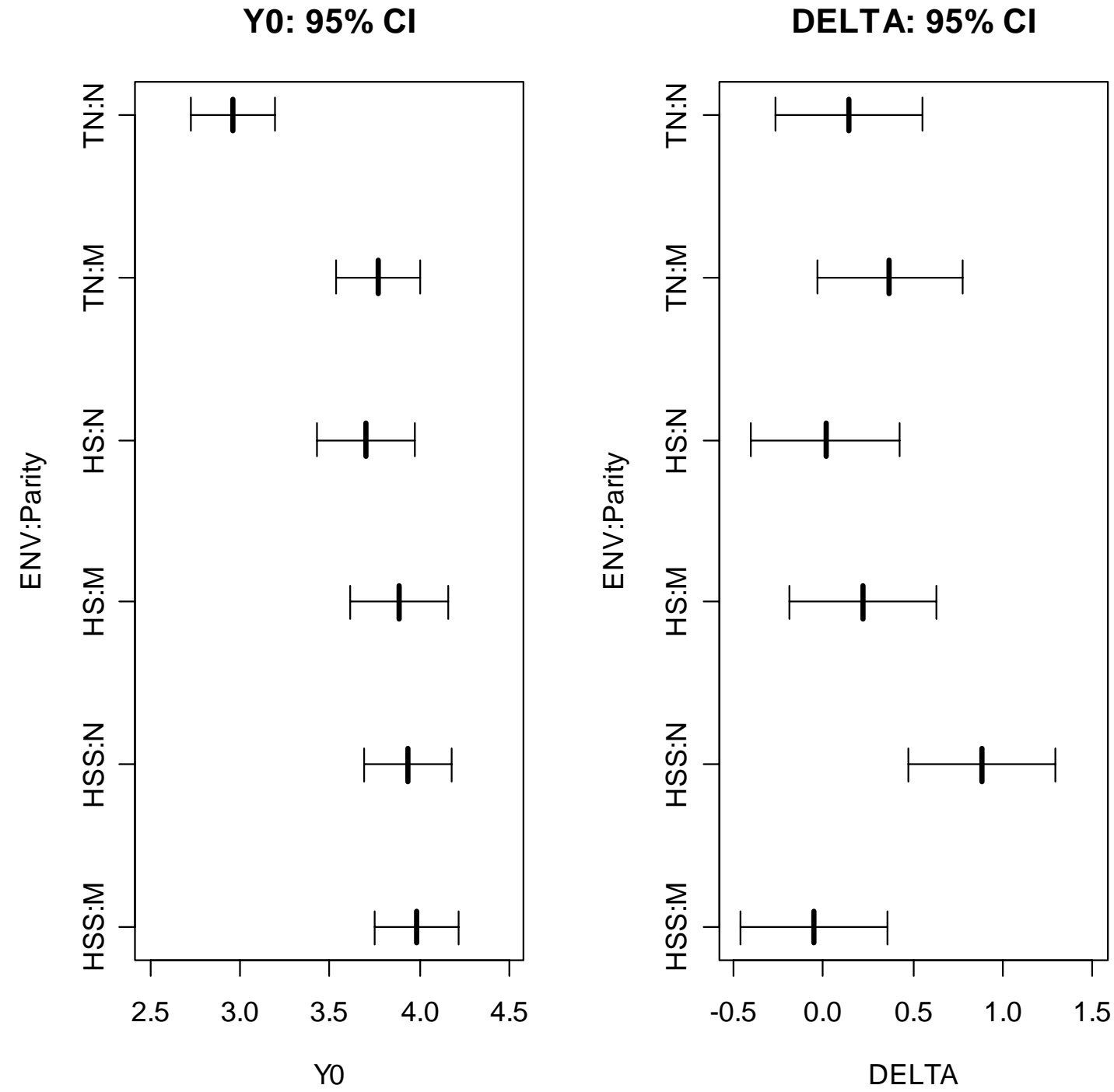


\section{CONCLUSIONS}

This study provides a four-parameter modified Gaussian model with both crossed and nested random effects to describe the circadian patterns of serum prolactin concentrations for three-way treatments applied in an incomplete crossover experiment. A description of the pattern will be described in the next section. This approach allows us to model response curves and test treatment effects simultaneously. Two parameters, initial and range of serum prolactin concentration, in the modified Gaussian model are considered as mixed effects and other two parameters, time to max concentration and rate constant, are considered as fixed effects. The cow-level random effects influence only the initial concentration parameter $\mathrm{Y} 0$; whereas period- and event-level random effects influence both the initial concentration and range parameters $\mathrm{Y} 0$ and $\Delta$ independently. The interaction between environment and parity had significant effect on both initial serum prolactin concentration (Y0) and range of the prolactin concentration $(\Delta)$ at $5 \%$ level. The initial concentration $\mathrm{Y} 0$ was significantly lower in TN-N than in other combinations of environment and parity. The range parameter $\Delta$ was significantly greater than zero only in HSS-N. There was no significant effect of recombinant bovine somatotropin (rbST) on either the initial value or concentration of serum prolactin. The carryover effect of HSS (Heat Stress plus Solar) on the initial concentration was detected, which significantly increased Y0. The presence of the significant carryover effect implies that the washout period in the experiment is insufficient.

\section{SUMMARY}

This study provides a four-parameter modified Gaussian model to describe the circadian patterns of serum prolactin concentrations in heated stressed Holsteins. This pattern can best be described in terms of the initial concentration of prolactin, time to maximum concentration, range, and factors that affect it. The mean level of initial serum prolactin concentration is $3.701 \log (\mathrm{ng} / \mathrm{ml})$. The time to maximum level of log-prolactin is 14.1, rate constant is $19.3 \mathrm{hr}^{-1}$ and the range is $0.266(\log (\mathrm{ng} / \mathrm{ml})$. Recombinant bovine somatotropin (rbST) did not affect the serum prolactin concentration. However, environment and parity did. The range of serum prolactin concentration was significantly higher $(0.883 \log (\mathrm{ng} / \mathrm{ml}))$ for nulliparous cow under solar hear stress. Examination of carry-over effects showed initial value of prolactin increased significantly to 4.068 $\log (\mathrm{ng} / \mathrm{ml})$ after exposure to solar heat stress and tests of interaction showed serum prolactin concentration was significantly lower $(2.963 \log (\mathrm{ng} / \mathrm{ml}))$ for nulliparous cows in a thermoneutral environment.

The crossed and nested random effects have been introduced into the model to simultaneously model the period, cow, and event variations. Comparisons of three-way treatment effects over time and testing of the first-order carryover effects are incorporated with the model building process. We present a general approach to multilevel nonlinear mixed effects model building and advocate in detail a way to simplify the random effect terms and the fixed effect structures. The primary advantage of this procedure is that it can be used to fit nonlinear mixed-effects models with complex random- and fixedeffects structures. 


\section{REFERENCES}

Rasbash, J. and Goldstein, H. 1994. Efficient Analysis of Mixed Hierarchical and CrossClassified Random Structures Using a Multilevel Model. Journal of Educational and Behavioural Statistics 19: 337-350.

Pinheiro, J.C. and D.M. Bates. 2000. Mixed-Effects Models in S and S-PLUS. New York: Springer-Verlag.

R Development Core Team. 2004. R: A Language and Environment for Statistical Computing. R Foundation for Statistical Computing, Vienna, Austria. ISBN 3-90005107-0, URL http://www.R-project.org.

SAS Institute. 2004. SAS OnlineDoc, Version 9.1.3, Cary, NC: SAS Institute Inc.

Skaug, H. and Fournier, D. 2006. Random effects in AD Model Builder (ADMB-RE) User Guide. Otter Research Ltd., Canada.

Wolfinger, R. 1993. Laplace's approximation for nonlinear mixed models. Biometrika 80: 791-795.

Zhou, M., Parkhurst, A.M., Eigenberg, R.A., Nienaber, J.A. and Hahn, G.L. 2006. Evaluating nonlinear crossed random effects models for comparing temperature of eating pigs under different thermal environments. Proceedings of Eighteenth Annual Kansas State University Conference on Applied Statistics in Agriculture Proceedings. 


\section{APPENDIX: The NLME code for fitting the nonlinear mixed-effects model formulated by Eq. 1 and Eq. 2 without treatments and covariates assuming diagonal $D_{\text {COW, }} D_{\text {PER, and }} D_{E V T}$, and independent errors (e.g. $\Psi=\mathrm{I}$ )}

\# Event is specified as the lowest hierarchical level grouping factor \# (hierarchical level 1 grouping factor)

\# Specify Cow as a standard hierarchical level 2 grouping factor

\# Create a new grouping factor as the highest hierarchical level

\# (hierarchical level 3 grouping factor) with one level spanning the entire data set newGF <- factor(rep(1,length(hormone.prl\$Y)))

\# Specify that each level of Period has a coefficient random at newGF

\# " -1 " indicates that the specific term factor(Period ) does not have an intercept

\# Cannot estimate the correlation associated with Period

full.nlme $<-$

nlme $($ model $=Y \sim Y 0+D E L T A * \exp (-(X-T A U) * * 2 / G A M M A)$, fixed $=\mathrm{Y} 0+\mathrm{DELTA}+\mathrm{TAU}+\mathrm{GAMMA} \sim 1$, random $=\operatorname{list}($ newGF $=$ pdIdent $(Y 0 \sim$ factor(Period) -1$)$, newGF $=$ pdIdent(DELTA $\sim$ factor(Period) -1$)$, newGF $=$ pdIdent(TAU factor(Period)-1), newGF=pdIdent(GAMMA factor(Period)-1), Cow $=$ pdDiag(Y0+DELTA+TAU+GAMMA 1), Event $=\operatorname{pdDiag}(\mathrm{Y} 0+\mathrm{DELTA}+\mathrm{TAU}+\mathrm{GAMMA} \sim 1))$, $\operatorname{start}=\mathrm{c}(4, .3,14,18)$, data $=$ hormone.prl $)$ 